\title{
Design and research of double-position automatic bagging machine based on PLC and HMI
}

\author{
Xiaoguang Li \\ School of Mechanical Engineering \\ Hubei University of Technology \\ Wuhan,China \\ e-mail:lxg_126@sina.com
}

Gang $\mathrm{Hu}$

Hubei Mechanical and Electrical Research and Design

Institute Co.,Ltd.

Wuhan, China

e-mail:hugang982@163.com

\author{
Fei Zhong \\ School of Mechanical Engineering \\ Hubei University of Technology \\ Wuhan,China \\ e-mail:hg_zfxs@sina.com
}

\begin{abstract}
In order to solve the inefficiencies, labor-intensive, inconsistent quality and other shortcomings in traditional package bag artificial production, a prototype of doubleposition automatic bagging machine based on Omron PLC and HMI was developed by the authors.Considering both industrial site requirements and experimental analysis, the authors put forward a new operation mode of doubleposition.The bagging machine control strategy are analyzed.Not only the control method of hardware system are discussed, but also the software of control system are introduced.Using PLC as the core controller can guarantee the accuracy of site control, stability and real-time, but also has good scalability and portability features.Composed of servo encoder feedback loop form a closed loop control system, which achieves the accurate and stable control of the system.Practical operation effect shows that the machine is running high reliability, friendly man-machine interface, greatly improve the efficiency of the sack, reduces the labor intensity, has a broad market prospect.
\end{abstract}

Keywords- PLC; HMI;double-position ; automatic ; AC servo motor

\section{INTRODUCTION}

With a lot of need for packaging products, packaging machinery and equipment demand is also growing.However, the late development of China's packaging machinery, low level of automation, far behind the developed countries[1].Automation technology as a key technology development of packaging machinery has been paid attention to by the people in the industry[2].

Composite bags is a kind of important packaging products which is consists of inner bag and outer bag.It is need to artificial put the inner bag(five co-extruded blown film bag) into outer bag(paper-plastic bag) within the processing.And then move the bags to the sewing machine to sew the bottom of the bags. The whole process takes 3-4 people together to complete.This processing method is slow, labor intensive, difficult to guarantee product quality.Combined with enterprise requirements, this paper proposes a double-position automatic bagging machine based on PLC and HMI design scheme.It is also made a detailed introduction about hardware and software of the control system .

\section{OVERALL SCHEME DESIGN}

\section{A. Organizations And Control Strategy}

Double-position automatic bagging machine is composed of six institutions.Institutions function schematic is shown in Fig.1:

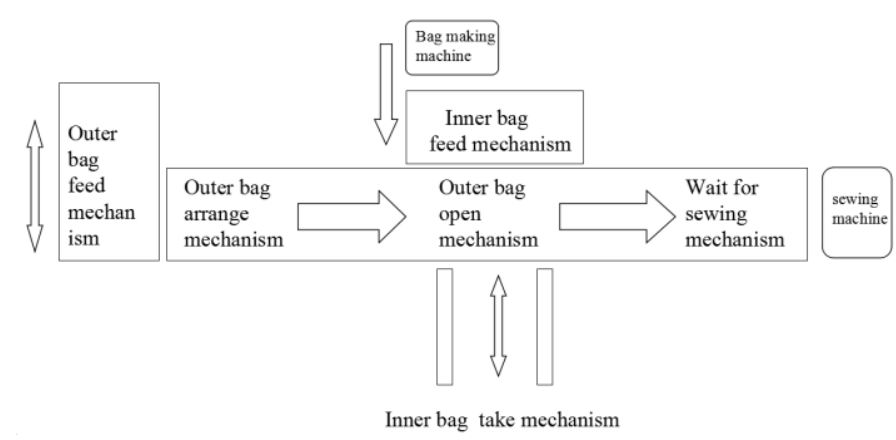

Figure 1. Institutions function schematic

- Outer bag feed mechanism:Made up of two same bin rolling cars and rail,used to hold the outer bags.

- Outer bag arrange mechanism:Foreign outer bag for horizontal and vertical orientation, and make the two outer bag has a certain positional relationship.

- Outer bag open mechanism:Through the up and down two sets of chuck bag open, to prepare for the set of inside the bag. 
- Inner bag feed mechanism:Bag making good mechanism inside the bag after, will be within the bag according to certain position for flat side by side, waiting for fetching.

- Inner bag take mechanism:Through the servo motors and claw clips to take inner bag into open outer bags.

- Wait for sewing mechanism:Move the bag into the sewing machine has been completed by belts.

The control strategy of double-position automatic bagging machine is: First, outer bag feed mechanism through worm gear mechanism rise outer bag to a certain height,and through suckers and grippers to clamp the outer bag to outer bag arrange mechanism.Then push the edge of the cylinder transverse and longitudinal interception cylinder on the outer bag arrange mechanism for positioning the two outer bag and rotating cylinder driven by a servo motor and drag to outer bag open mechanism.Outer bag will be opened by two sets of vacuum pressure through the suction cups on outer bag open mechanism.And then claw clips drive by the servo motors on inner bag take mechanism will grab the inner bags.At last ,two have finished bags will be moved by servo motor into belts, and wait for sewing.

\section{B. Main Technical Parameters And Requirements}

According to company requirements, the machine needs to satisfy the following conditions:

- The length of pull the bag can be regulated in $\pm 20 \mathrm{~mm}$.

- Reserve the position of a inner bag making machine and sewing machine.

- PLC control, touch screen monitors, build human-machine interface.

The main technical parameters of double-position automatic bagging machine is shown in table. I :

TABLE I. INDEX PARAMETERS

\begin{tabular}{|c|c|}
\hline & Index parameters \\
\hline Production speed & $20-30 /$ min \\
\hline Inner-bag specification $(\mathrm{mm})$ & $820 * 550(\mathrm{~L} * \mathrm{~W})$ \\
\hline Outer-bag specification $(\mathrm{mm})$ & $1020 * 560(\mathrm{~L} * \mathrm{~W})$ \\
\hline
\end{tabular}

\section{CONTROL SYSTEM HARDWARE DESIGN}

The control system of double-position automatic bagging machine based on PLC and HMI have many actions at work and between each action has a strict and logical order.In order to guarantee the accuracy of system control,PLC output pulse and direction signals to drive the servo motor, the control precision of servo motor movement[3].Using industrial touch screen to achieve human-computer interaction interface, complete the system parameter setting, on-line debugging[4].At the same time, choose solenoid valves and sensors as control system hardware.The overall control scheme of double-position automatic bagging machine is shown in Fig .2:

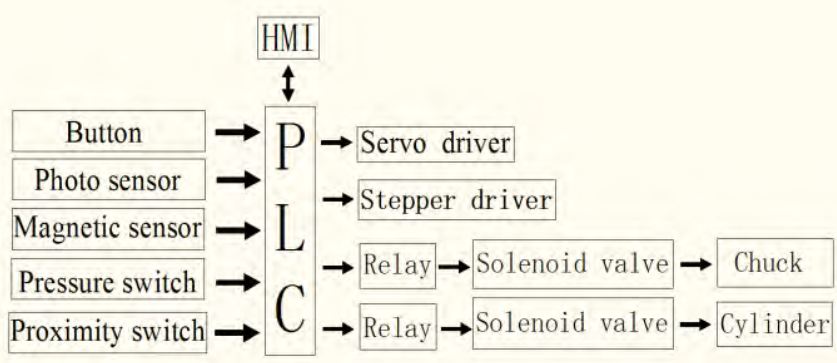

Figure 2. Overall control scheme

\section{A. Selection Of PLC And I/O Allocation}

The overall design scheme can determine the number of each mechanism of the motor shaft and the PLC input and output points.As shown in table II :

\begin{tabular}{|l|l|l|l|}
\hline & $\begin{array}{l}\text { NO.of } \\
\text { motors }\end{array}$ & $\begin{array}{l}\text { PLC input } \\
\text { points }\end{array}$ & $\begin{array}{l}\text { PLC output } \\
\text { points }\end{array}$ \\
\hline $\begin{array}{l}\text { Outer bag feed } \\
\text { mechanism }\end{array}$ & 2 & 10 & 10 \\
\hline $\begin{array}{l}\text { Outer bag } \\
\text { arrange } \\
\text { mechanism }\end{array}$ & 1 & 28 & 8 \\
\hline $\begin{array}{l}\text { Outer bag open } \\
\text { mechanism }\end{array}$ & 1 & 24 & 7 \\
\hline $\begin{array}{l}\text { Wait for sewing } \\
\text { mechanism }\end{array}$ & 0 & 10 & 5 \\
\hline $\begin{array}{l}\text { Inner bag take } \\
\text { mechanism }\end{array}$ & 2 & 14 & 2 \\
\hline $\begin{array}{l}\text { Inner bag feed } \\
\text { mechanism }\end{array}$ & 1 & 13 & 3 \\
\hline Total & 7 & 99 & 35 \\
\hline
\end{tabular}

TABLE II . N NUMBER OF MOTORS AND I/O POINTS OF PLC

PLC manufacturers now have a lot of common with Omron, Mitsubishi, Delta, etc.Known from Table 2, PLC require a total of 99 inputs and 35 outputs, motor control 7.At the same time need to use a touch screen as the display terminal.Since the servo motor control needs a lot high speed pulse as output, decided to use Omron CP1H-Y20DT-D-type PLC and CJ1W-NC433type position control module. With the use of CP1W40EDR type $\mathrm{I} / \mathrm{O}$ expansion modules as the master unit.

$\mathrm{CP} 1 \mathrm{H}$ type PLC is multi-function equipment,embedded 2-axis $1 \mathrm{MHz}, 2$-axis $100 \mathrm{kHz}$ high-speed pulse output. CJ1W-NC433 Position 
Control module type has a 4-axis pulse train output linear drive, has high reliability, high precision and strong control ability.Chooses omron NB10W-TW01B touch screen and PLC communication, using RS232 serial port communication connection for data transmission[5.6].

Due to excessive input and output points listed in this article I / O ports, as shown in table III:

TABLE III PART I/O ALLOCATION

\begin{tabular}{|l|l|l|l|}
\hline $\begin{array}{l}\text { Input } \\
\text { point }\end{array}$ & Introduce & $\begin{array}{l}\text { Output } \\
\text { point }\end{array}$ & Introduce \\
\hline 4.05 & $\begin{array}{l}\text { Situ position of } \\
\text { push cylinder }\end{array}$ & 105.00 & $\begin{array}{l}\text { 1\#Take } \\
\text { cylinder }\end{array}$ \\
\hline 4.06 & $\begin{array}{l}\text { End position of } \\
\text { push cylinder }\end{array}$ & 105.01 & $\begin{array}{l}\text { 2\#Take } \\
\text { cylinder }\end{array}$ \\
\hline 6.07 & $\begin{array}{l}\text { Situ position of } \\
1 \# \text { \#pen cylinder }\end{array}$ & 105.04 & $\begin{array}{l}\text { Push } \\
\text { cylinder }\end{array}$ \\
\hline 6.08 & $\begin{array}{l}\text { End position of } \\
1 \# \text { open cylinder }\end{array}$ & 106.02 & $\begin{array}{l}\text { 1\#Open } \\
\text { cylinder }\end{array}$ \\
\hline 9.06 & $\begin{array}{l}1 \# \text { Promixity } \\
\text { switch }\end{array}$ & 106.03 & $\begin{array}{l}\text { 2\#Open } \\
\text { cylinder }\end{array}$ \\
\hline 9.11 & $\begin{array}{l}1 \# \text { Photo sensor } \\
106.05\end{array}$ & $\begin{array}{l}\text { 1\#Solenoid } \\
\text { valve }\end{array}$ \\
\hline 11.05 & $\begin{array}{l}\text { 1\#Pressure } \\
\text { switch }\end{array}$ & 106.06 & $\begin{array}{l}\text { 2\#Solenoid } \\
\text { valve }\end{array}$ \\
\hline
\end{tabular}

\section{B. Servo Motor Matching Calculation [7.8]}

In order to meet the mechanical requirements of high precision control,need to selection of closed-loop control system constituted by a servo motor encoder feedback loop formation.Taking 1 \# servo motor as an example, carries on the rated speed and torque of the matching calculation.

1) rated speed matching calculation

By the formula:

$$
N=\frac{V}{\pi P_{D}} n
$$

Here, $\mathrm{N}$ is the desired minimum speed of servo motor. $\mathrm{V}$ is the linear velocity, taking $\mathrm{V}=1 \mathrm{~m} / \mathrm{s} ; P_{D}$ for pulley diameters, taking $=0.05 \mathrm{~m} ; \mathrm{n}$ is reducer reduction ratio, taking $\mathrm{n}=6$.Calculated, $\mathrm{N} \approx 22 \mathrm{r} / \mathrm{s}$.

2) Rated torque matching calculation

Servo motor output torque curve by acceleration, deceleration and constant speed of three parts.

a) When the servo motor uniform motion, by the formula:

$$
T_{f}=\frac{P_{D}}{2 \eta n}\left(g W_{A}+F\right)
$$

$T_{f}$ known as uniform when the servo motor torque required to move.Wherein, $\eta$ means mechanical efficiency, take $\eta=0.8 ; W_{A}$ means load quality,take $W_{A}=5 \mathrm{~kg}$. Calculated, $T_{f} \approx 0.3 \mathrm{~N} \cdot \mathrm{M}$.

b) When the servo motor acceleration, by the formula:

$$
T_{a}=\frac{\left(J_{L}+J_{M}\right) 2 \pi N}{T_{1}}+T_{f}
$$

$T_{a}$ known as the required torque to move the servo motor during acceleration. Wherein the rotational load of the servo motor inertia is $J_{L}=11.5 \times 10^{-4} \mathrm{~kg} \cdot \mathrm{m}^{2}$, the servo motor rotor inertia is $J_{M}=0.7 \times 10^{-4} \mathrm{~kg} \cdot \mathrm{m}^{2} . T_{1}$ is acceleration time,take $T_{1}=0.2 \mathrm{~s}$, Calculated, $T_{a} \approx 1.1 \mathrm{~N} \cdot \mathrm{M}$.

c) When the servo motor deceleration, by the formula:

$$
T_{d}=\frac{\left(J_{L}+J_{M}\right) 2 \pi N}{T_{2}}-T_{f}
$$

$T_{a}$ known as the required torque to move the servo motor during deceleration. $\boldsymbol{T}_{2}$ is deceleration time, take $T_{2}=0.2 \mathrm{~s}$, Calculated, $T_{d} \approx 0.6 \mathrm{~N} \cdot \mathrm{M}$.

Based on the above calculations, 1 \# servo motor rated torqueT $\geqslant T_{a}=1.1 \mathrm{~N} \cdot \mathrm{M}$.

By the above matching calculation, we know system required minimum speed and torque respectively $22 \mathrm{r} / \mathrm{s}$ and $1.1 \mathrm{~N} \cdot \mathrm{M}$.Consider the costs and business requirements, use Panasonic A5 series servo motors, model MHMD042G1U.Its rated speed and torque were $60 \mathrm{r} / \mathrm{s}$ and $1.3 \mathrm{NM}$, were greater than the required design to meet the requirements.

\section{CONTROL SYSTEM SOFTWARE DESIGN}

The software design including PLC programming control system and human-machine interface configuration.

\section{System Control Software [9]}

System control software has a main program and a number of subroutines.Including system initialization procedure;Motor parameter settings and logic control program:Start and stop the machine and mode selection;Stepper motor program (stepper motor initialization, fixed-length control, etc.); servo motor program (servo motor initialization, servo homing, etc.); outer bag finishing program (using cylinder interception and push the edge, external pocket for horizontal and vertical positioning ); inside the bag taking program (using servo motor direction plus pulse mode operation to achieve the bag kit bag); communication program (using the RS-232 for communication between PLC and touch screen),etc.Control software flow chart shown in Fig .3: 


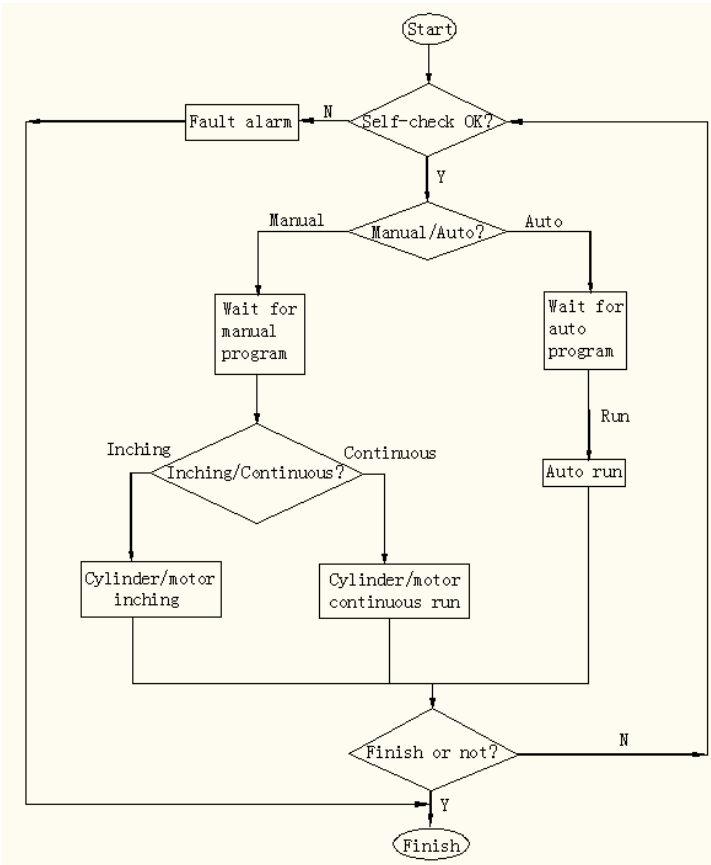

Figure 3. Control software flow chart

\section{D. human-computer interface design}

Human Machine Interface (HMI) device is a bridge between the user and the machine can be flexibly applied graphics and text information related to replace traditional equipment on a large number of touch buttons, lights, selector switches, etc. [10.11]. This design uses special software NB-Designer Omron each interface configuration. Man-machine interface systems, including the main interface, parameter setting interface, automatic operation interface, manually run the interface, etc., as shown in Fig .4:

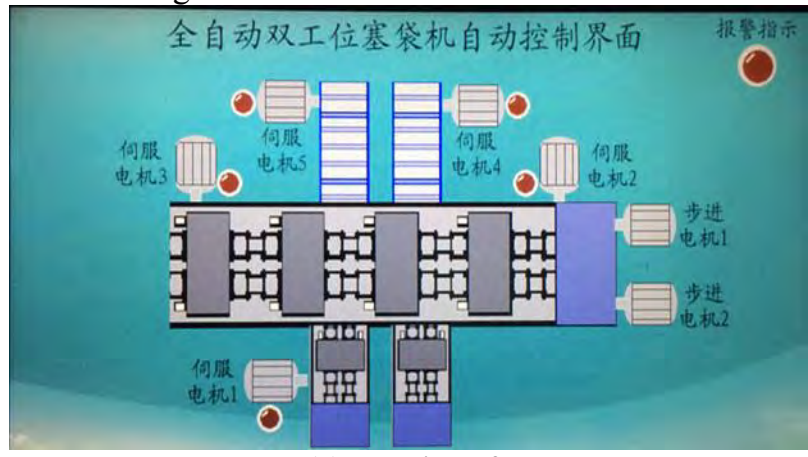

(a)Auto interface

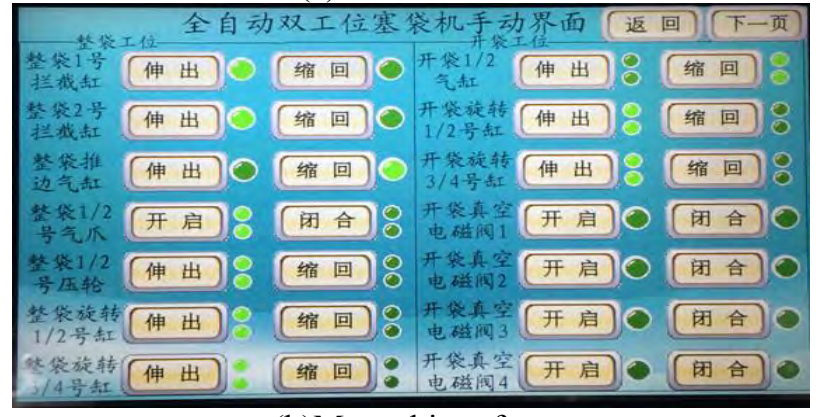

(b)Manual interface

Figure 4. System Interface
After the system boot initialization is complete, enter the main interface. The main interface: the interface is responsible for each master switch; parameter setting interface: for servo motor parameter settings and status display; autorun interface: Displays the status of the machine automatically at runtime; manual interface: Point sucker for cylinders and moving; alarm interface : used to display the servo motor failure alarm information.

\section{CONCLUSION}

After the completion of the system design, carried out several simulation experiments, and considering the scene may appear improved. The system is reliable, has a certain flexibility to adapt to different kinds of bags. Employment numbers increased from 3 to 4 people reduced to two people, a high degree of automation. The actual operation shows that the production rate of the device, the production quality has been greatly improved, with a wide range of promotional sense.

\section{ACKNOWLEDGMENT}

This work is supported by University-enterprise cooperation projects of Hubei University of Technology under Grant 309.795.

\section{REFERENCES}

[1] L.Zhu, "Analysis on present situation and development trend of domestic candy packaging,"Packaging Engineering,vol.30,no.6,pp.87-89,2009.

[2] L.Han,R.J.Lu,"Profile of Bag-making machine detection and development of control technique,"Packaging Engineering, vol.31,no.11,pp.135-139,2010.

[3] Q.D.Guo ,Ac Servo System,Beijing,Mechanical industry press, 1994.

[4] F.G.Qiu,"Composite applications of Omron PLC and Delta HMI ,'International Mechatronics Technology,vol.04,pp.2022,2009.

[5] G.P.Zhou, D.Q.Shen,"Design of wallpaper packaging contro system based on PLC ," Packaging Engineering, vol.33,no.9,pp.108-110,2012.

[6] Ziemba, Robert."Use of a programmable logic controller (PLC) for temperature, position, velocity and pressure control of injection molding machinery,"Conference Record - IAS Annual Meeting, 1988.

[7] J.F.Wang,H.Tang,"The choice of nc machine tool feed servo motor,"Equipment Manufacturing Technology,vol.11,pp.129$131+133,2009$.

[8] W.X.Guo,"The choice of nc machine tool feed servo motor,"Mechanical Research \&Application,vol.02,pp.13-15,1996.

[9] S.Y. Liu, "Design of Control system of collective packing machine Based on PLC,'Packing Engineering,vol.03,pp.5,2009.

[10] T.F.Cai , J.Z.Zhou,"Monitor system for automatic grouting of metamorphic concrete based on PLC and HMI,"Applied Mechanics and Materials, pp.662-665,2013.

[11] S.Y.Lei,"Servo-control system design of automatic production line based on PLC and HMI," Applied Mechanics and Materials,pp.1381-1385,2014 